\title{
Qualidade de grãos de milho armazenados em diferentes temperaturas
}

\author{
Ricardo T. Paraginski ${ }^{1}$, Bruno A. Rockenbach ${ }^{2}$, Rodrigo F. dos Santos ${ }^{3}$, \\ Moacir C. Elias $^{4} \&$ Maurício de Oliveira ${ }^{5}$
}

\section{Palavras-chave:}

resfriamento

umidade

classificação

óleo

\begin{abstract}
R E S U M O
A temperatura de armazenamento é um dos principais fatores que interferem na qualidade de armazenamento e, considerando a pequena quantidade de trabalhos realizados com grãos de milho, este estudo objetivou avaliar a qualidade de grãos de milho armazenados nas temperaturas de $5,15,25$ e $35^{\circ} \mathrm{C}$, durante 12 meses. Foram realizadas análises de classificação dos grãos, teor de água, peso de mil grãos, percentual de germinação, condutividade elétrica e teor de lipídios no início, aos 3, 6, 9 e 12 meses de armazenamento; a análise de perfil de ácidos graxos foi realizada no início e ao final dos 12 meses. Os grãos foram classificados como Tipo 1 até os 6 meses de armazenamento porém após este período ocorreu uma redução drástica na qualidade sendo enquadrados como abaixo do padrão na temperatura de $25^{\circ} \mathrm{C}$. Os resultados de teor de água, peso de mil grãos, germinação, condutividade elétrica e perfil de ácidos graxos indicaram que as maiores alterações foram observadas nos grãos armazenados nas temperaturas mais elevadas principalmente a 25 e $35^{\circ} \mathrm{C}$ indicando que o tempo de armazenamento seguro dos grãos nessas condições é menor quando comparado ao armazenamento em temperaturas mais baixas.
\end{abstract}

\section{Key words:}

cooling

moisture

classification

oil

\section{Quality of maize grains stored at different temperatures}

\begin{abstract}
A B S T R A C T
The storage temperature is one of the main factors that affect the quality of storage, and considering the fact that limited studies have been conducted with maize, this study aimed to evaluate the quality of maize grains stored at $5,15,25$ and $35^{\circ} \mathrm{C}$ for 12 months. Analysis for classification of grain, moisture content, thousand grain weight, germination percentage, electrical conductivity and lipid content at the beginning, at 3, 6, 9 and 12 months of storage, and analysis of fatty acid profile were performed at the beginning and at the end of 12 months. The grains were classified as Type 1 until 6 months of storage, but after this period there was a drastic reduction in quality, being framed with below standard temperature of 25 ${ }^{\circ} \mathrm{C}$. The results of water content, thousand grain weight, germination, electrical conductivity, and fatty acid profile indicated that major changes were observed in grain storage at higher temperatures, especially at 25 and $35^{\circ} \mathrm{C}$, indicating that the safe time for storage of grains under these conditions is less compared to storage at lower temperatures.
\end{abstract}

Protocolo 417-2013 - 19/12/2013 • Aprovado em 05/12/2014 • Publicado em 02/03/2015

${ }^{1}$ Instituto Federal Farroupilha. Alegrete, RS. E-mail: paraginskiricardo@yahoo.com.br (Autor correspondente)

${ }^{2}$ UFPel. Pelotas, RS. E-mail: brunorockenbach7@hotmail.com

${ }^{3}$ UFPel. Pelotas, RS. E-mail: rodrigof.agronomia@gmail.com

${ }^{4}$ Departamento de Ciência e Tecnologia Agroindustrial/UFPel. Pelotas, RS. E-mail: eliasmc@ufpel.tche.br

${ }^{5}$ Departamento de Ciência e Tecnologia Agroindustrial/UFPel. Pelotas, RS. E-mail: oliveira.mauricio@hotmail.com 


\section{INTRODUÇÃo}

A produção brasileira de grãos de milho (Zea mays L.) foi, na safra de 2012/2013, de aproximadamente 81 milhões de toneladas (CONAB, 2013) sendo este total de produção utilizado em diferentes setores, como alimentação animal, industrialização ou consumo in natura, apesar dos grãos não possuírem, ainda, qualidade elevada para atender à necessidade dos consumidores. Grãos de milho são produzidos em duas safras e carecem de armazenamento durante o restante do período do ano para atender à demanda; entretanto, muitas vezes por déficit de armazenamento ou mesmo por falta de informações, os grãos acabam sendo armazenados de forma incorreta, em condições inadequadas, o que acaba comprometendo a qualidade do produto.

A temperatura é um dos principais fatores que interferem na qualidade de armazenamento de grãos (Rehman et al., 2002; Reed et al., 2007; Park et al., 2012), sendo que nos últimos anos vem crescendo a utilização da tecnologia de resfriamento artificial em grãos, com o objetivo de preservar a qualidade do produto por períodos mais elevados e reduzir a deterioração dos grãos. Esta técnica consiste em refrigerar os silos utilizados para armazenamento caracterizados como sistema semi-hermético pois permitem trocas de ar entre o ambiente e o interior da massa de grãos, sendo insuflado ar refrigerado para o interior do silo, pelo sistema de aeração, permanecendo este em funcionamento até a massa dos grãos possuir níveis desejados de temperatura.

A redução da temperatura dos grãos diminui a velocidade das reações bioquímicas e metabólicas dos grãos, pelas quais reservas armazenadas no tecido de sustentação são desdobradas, transportadas e ressintetizadas no eixo embrionário (Santos et al., 2004; Perez-Garcia \& GonzalezBenito, 2006; Aguiar et al., 2012), permitindo a manutenção das características inicias de armazenamento dos grãos por períodos mais longos, sendo que alguns trabalhos com uso de resfriamento artificial já foram realizados em grãos de feijão, soja e arroz (Brackmann et al., 2002; Rigueira et al., 2009; Oliveira et al., 2011; Park et al., 2012) porém poucos trabalhos foram realizados com grãos de milho.

Desta forma e considerando o crescimento da utilização do resfriamento artificial de grãos no Brasil com o objetivo de reduzir as perdas qualitativas nos grãos, a importância dos grãos de milho em diferentes setores agroindustriais e a temperatura como um dos principais fatores que interferem na qualidade de armazenamento objetivou-se avaliar, no estudo, os efeitos das temperaturas de $5,15,25$ e $35^{\circ} \mathrm{C}$ na qualidade tecnológica de grãos de milho ao longo de 12 meses de armazenamento.

\section{Material e Métodos}

Utilizaram-se grãos de milho do grupo semi-duro, classe amarela, produzidos em 2012 no município de Santo Augusto, estado do Rio Grande do Sul, Brasil, latitude S $27^{\circ} 53^{\prime} 18^{\prime \prime}$, longitude W $53^{\circ} 47^{\prime} 20^{\prime \prime}$ e altitude de $489 \mathrm{~m}$. Os grãos foram colhidos mecanicamente, submetidos à secagem artificial com temperatura do ar de $35^{\circ} \mathrm{C}$ até teor de água de $14 \%$, e posteriormente submetidos a expurgo com fosfeto de alumínio
(Gastoxin B57) para inibir a interferência de insetos nos grãos durante o armazenamento. Os grãos foram armazenados nas temperaturas de $5,15,25$ e $35^{\circ} \mathrm{C}$ durante 12 meses, ao abrigo da luz em sacos de polietileno de $0,2 \mathrm{~mm}$ de espessura de filme plástico com capacidade de $0,9 \mathrm{~kg}$, no Laboratório de Pós-Colheita, Industrialização e Qualidade de Grãos, DCTA-FAEM-UFPel em sistema semi-hermético sendo que, periodicamente e a cada 45 dias, os sacos foram abertos para os grãos serem aerados simulando o que ocorre nos sistemas de armazenamento a granel, em silos verticais e horizontais. As avaliações foram realizadas no início, aos 3, 6, 9 e 12 meses, exceto no perfil de ácidos graxos, quando foi realizada avaliação no início e ao final de doze meses de armazenamento.

A classificação dos grãos foi realizada por classificador oficial de grãos registrado no MAPA - Ministério da Agricultura Pecuária e Abastecimento, com número EAC 1.867, de acordo com a Instrução Normativa MAPA n ${ }^{\circ} 60$, de 22 de dezembro de 2011, publicada no D.O.U de 23.11.2011. Os defeitos identificados e pesados para tipificação foram ardidos, chochos, imaturos, fermentados, germinados, gessados e mofados.

Para determinação do teor de água foi utilizado o método de estufa com circulação de ar, na temperatura de $105 \pm 1{ }^{\circ} \mathrm{C}$, durante $24 \mathrm{~h}$, em três repetições, de acordo com recomendações da American Society of Agricultural Engineers (ASAE, 2000).

O peso de 1000 grãos foi determinado com contagem de 8 repetições de 100 grãos e pesagem em balança analítica (Brasil, 2009). Os resultados foram expressos em gramas.

O teor de germinação foi conduzido em quatro repetições de 50 sementes por lote, em rolo de papel toalha, em germinador regulado a $25^{\circ} \mathrm{C}$, embebido em água na quantidade de 2,5 vezes o peso do substrato seco visando umidecimento adequado com as contagens feitas no $5^{\circ}$ dia após a semeadura, seguindo as Regras para Análise de Sementes (Brasil, 2009). Os resultados foram expressos em percentagem pela média das repetições.

A condutividade elétrica da água de hidratação foi determinada segundo metodologia do ISTA (2008), quando foram contadas 4 repetições de 25 grãos pesados e imersos em $75 \mathrm{~mL}$ de água deionizada (em becker de $250 \mathrm{~mL}$ ), colocados em germinador regulado para a temperatura constante de 20 ${ }^{\circ} \mathrm{C}$ e posteriormente incubados durante $24 \mathrm{~h}$. As soluções foram agitadas suavemente e a condutividade elétrica foi determinada com condutivímetro sem filtragem da solução. Os resultados foram expressos em $\mu \mathrm{S} \mathrm{cm}^{-1} \mathrm{~g}^{-1}$.

O teor de lipídios foi determinado de acordo com método da AACC 30-20 (AACC, 1995).

O Perfil de ácidos graxos foi determinado segundo metodologia de Hartman \& Lago (1973), sendo dividido nas etapas de derivatização e análise cromatográfica.

Quanto à derivatização, foram pesados 0,03 g de óleo em tubo de ensaio adicionados $500 \mu \mathrm{L}$ de $\mathrm{KOH} \mathrm{0,1} \mathrm{N} \mathrm{em} \mathrm{metanol}$ deixando-se em banho-maria a $60^{\circ} \mathrm{C}$ por $1,5 \mathrm{~h}$. Após esfriar, adicionou-se $1,5 \mathrm{~mL}$ de $\mathrm{H}_{2} \mathrm{SO}_{4} 1 \mathrm{M}$, sendo novamente levadas ao banho-maria a $60{ }^{\circ} \mathrm{C}$ por mais $1,5 \mathrm{~h}$; após esfriar, foram adicionados $4 \mathrm{~mL}$ de $\mathrm{n}$-hexano, agitando-se vigorosamente os tubos e só então coletado $1 \mathrm{~mL}$ da fase de n-hexano que contém os ésteres metílicos de ácidos graxos.

Para identificação e quantificação dos ésteres metílicos de ácidos graxos foi injetado $1 \mu \mathrm{L}$ em cromatógrafo gasoso, equipado com o detector de ionização de chama (FID) e 
coluna capilar Supelco SP2340 (60 m x 0,25 mm x 0,2 $\mu \mathrm{m})$. As temperaturas do detector e injetor foram 260 e $240{ }^{\circ} \mathrm{C}$. A programação de aquecimento da coluna foi iniciada com 140 ${ }^{\circ} \mathrm{C}$ por 5 min e aumento gradual de $4{ }^{\circ} \mathrm{C} \mathrm{min}^{-1}$ até a temperatura final de $240{ }^{\circ} \mathrm{C}$ permanecendo assim durante $5 \mathrm{~min}$. O fluxo do gás de arraste $\left(\mathrm{H}_{\mathrm{e}}\right)$ foi de $17 \mathrm{~mL} \mathrm{~min}^{-1}$. O volume de injeção foi de $0,5 \mu \mathrm{L}$ com razão de split de 1:100. A identificação dos picos foi efetuada pela comparação dos tempos de retenção com padrões de ésteres metílicos (Supelco 37 components FAMEs Mix, ref. 47885-U). A quantificação foi determinada pela área do pico do éster metílico de interesse, em relação à área total dos picos identificados e os resultados expressos em percentagem.

O delineamento inteiramente casualizado foi utilizado com três repetições para cada temperatura em cada tempo de coleta. Realizou-se análise de variância ANOVA, a 5\% de probabilidade para as variáveis utilizando-se software SAS Institute (2002).

\section{Resultados e Discussão}

Quanto ao tipo, os resultados de classificação dos grãos (Tabela 1) indicam que até os 6 meses de armazenamento os grãos foram classificados como Tipo 1, em todas as temperaturas de armazenamento; entretanto, dos 6 aos 12 meses de armazenamento houve uma redução da qualidade do produto sendo esses classificados como Abaixo do Padrão e Tipo 3, nas temperaturas de 25 e $35^{\circ} \mathrm{C}$, respectivamente, ao final de 12 meses de armazenamento sendo classificados, como Tipo 1, apenas os armazenados na temperatura de $15^{\circ} \mathrm{C}$.

Os resultados diferem dos encontrados por Costa et al. (2010), que classificaram os grãos de milho armazenados em sistema hermético com teor de água de 14,5\% em temperatura de $35{ }^{\circ} \mathrm{C}$ como Tipo 3 aos 6 meses; já neste estudo os grãos foram classificados como Tipo 1. Esta diferença na tipificação dos grãos pode ser atribuída à redução do teor de água dos grãos de 14,31 para $8,27 \%$ aos 6 meses de armazenamento (Figura 1A), reduzindo a atividade de água e, em consequência, as alterações enzimáticas, não enzimáticas e de microorganismos, obtendo-se um produto com melhor qualidade, ao contrário do sistema hermético, em que não houve alterações do teor de água justificando as maiores alterações observadas na qualidade do produto. A classificação dos grãos como Tipo 2 na temperatura de $5{ }^{\circ} \mathrm{C}$ aos 9 e 12 meses, pode ser atribuída à umidade elevada relativa do ar no ambiente visto ter sido realizado apenas controle de temperatura, ocorrendo um aumento da umidade relativa do ar acelerando os processos metabólicos e o desenvolvimento de micro-organismos nos grãos.

Tabela 1. Classificação dos grãos de milho armazenados durante 12 meses em sistema semi-hermético, de acordo com o regulamento técnico do MAPA (Brasil, 2011)

\begin{tabular}{cccccc}
\hline Temp. & \multicolumn{5}{c}{ Tempo de armazenamento (meses) } \\
\cline { 2 - 6 }$\left({ }^{\circ} \mathbf{C}\right)$ & $\mathbf{0}$ & $\mathbf{3}$ & $\mathbf{6}$ & $\mathbf{9}$ & $\mathbf{1 2}$ \\
5 & Tipo 1 & Tipo 1 & Tipo 1 & Tipo 2 & Tipo 2 \\
15 & Tipo 1 & Tipo 1 & Tipo 1 & Tipo 1 & Tipo 1 \\
25 & Tipo 1 & Tipo 1 & Tipo 1 & Tipo 3 & AP* \\
35 & Tipo 1 & Tipo 1 & Tipo 1 & Tipo 2 & Tipo 3 \\
\hline
\end{tabular}

* AP - Abaixo do padrão de comercialização
Os resultados de teor de água (Figura 1A) indicam que o teor de água não apresentou variação nos grãos armazenados nas temperaturas de 15 e $25{ }^{\circ} \mathrm{C}$ ao longo dos 12 meses de armazenamento porém houve aumento de $0,6 \%$ nos grãos armazenadosem temperatura de $5{ }^{\circ} \mathrm{C}$, a partir dos 6 meses de armazenamento chegando aos 12 meses com teor de água de $14,97 \%$. Na temperatura de $35{ }^{\circ} \mathrm{C}$ o valor reduziu de $14,31 \%$ no início do armazenamento para 7,79\% ao final de 12 meses estando de acordo, portanto, com estudos realizados por Faroni et al. (2005), que encontraram decréscimo no teor de água inicial de grãos de milho armazenados com 13,5\% durante 6 meses de armazenamento nas temperaturas de 30 e $40{ }^{\circ} \mathrm{C}$.

A redução do teor de água dos grãos observada nos grãos armazenados na temperatura de $35^{\circ} \mathrm{C}$ é resultado do equilíbrio higroscópico dos grãos com as condições do ambiente de armazenamento. Quando a pressão de vapor do grão é maior que a do ar circundante, ocorre o fenômeno de dessorção havendo transferência de vapor de água para o ar reduzindo, desta forma, a umidade dos grãos (Silva et al., 1995), sendo que vários fatores interferem no equilíbrio higroscópico de acordo com Carneiro et al. (2005), como composição química dos grãos, integridade física, estado sanitário, gradientes termo hídricos e operações de pós-colheita, dentre os quais a secagem e o armazenamento são as mais importantes.

Ao avaliar a composição nutricional de milho armazenado nas temperaturas de 10,25 e $45{ }^{\circ} \mathrm{C}$, Rehman et al. (2002) encontraram redução da umidade inicial de $12,38 \%$, para níveis de $12,00,9,32$ e 7,70\% para as respectivas temperaturas, ao final de 6 meses de armazenamento. Antonello et al. (2009) avaliaram sementes de milho armazenadas em embalagem plástica e de algodão com $13 \%$ de umidade mas não encontraram diferenças no teor de umidade durante 6 meses de armazenamento não comprometendo, porém, a qualidade da semente. De acordo com Rios et al. (2003), teor de água superior ao recomendado para o armazenamento seguro é uma das principais causas da perda das características tecnológicas dos grãos durante o armazenamento.

Os resultados de peso de 1000 grãos (Figura 1B) indicam que houve redução do peso de grãos armazenados na temperatura de $35{ }^{\circ} \mathrm{C}$ e um aumento a $5{ }^{\circ} \mathrm{C}$, resultado das alterações nos teores de água dos grãos (Figura 1A) e do consumo de reservas pelas atividade metabólicas. Os resultados encontrados na redução do peso de 1000 grãos estão de acordo com Antunes et al. (2011), que observaram redução ao avaliar grãos de milho durante o armazenamento; no entanto, o autor atribui esta redução ao ataque de insetos mas neste estudo não houve ataque de insetos e as reduções observadas são resultado da redução da umidade e também do aumento do processo respiratório dos grãos principalmente quando os grãos foram armazenados em temperatura de $35^{\circ} \mathrm{C}$.

Os resultados da Figura $1 \mathrm{C}$ indicam que houve redução do teor de germinação em todas as temperaturas de armazenamento sendo as maiores reduções verificadas na temperatura de $35^{\circ} \mathrm{C}$. O percentual de germinação dos grãos nas temperaturas de 5 e $15{ }^{\circ} \mathrm{C}$ não apresentou diferenças ao longo do armazenamento porém as reduções foram menores que na temperatura de $25{ }^{\circ} \mathrm{C}$ cujos níveis atingiram $73,75 \%$, uma redução de $13,24 \%$ ao final de 12 meses. Para os grãos armazenados na temperatura de $35^{\circ} \mathrm{C}$ o percentual de 



Figura 1. Teor de água (A), peso de mil grãos (B), germinação (C), condutividade elétrica (D) e teor de lipídios (E) de grãos de milho armazenados durante 12 meses nas temperaturas de $5,15,25$ e $35{ }^{\circ} \mathrm{C}$ germinação chegou a zero aos 90 dias de armazenamento. Resultados semelhantes foram encontrados por Costa et al. (2010), que também encontraram germinação igual a zero para grãos armazenados a $35^{\circ} \mathrm{C}$ com umidade de $14,5 \%$ porém diferiu quanto ao tempo encontrando esta redução após 135 dias de armazenamento.

A redução do teor de germinação dos grãos decorre das alterações que ocorrem na estrutura das membranas dos grãos sendo que, quando a temperatura e a umidade dos grãos são elevadas, as alterações são mais significativas resultando em perda da qualidade final do produto em curtos períodos de tempo. As sementes e/ou grãos passam, quando armazenados, a germinar mais lentamente que as sementes novas pois respiram mais lentamente e se tornam mais suscetíveis às doenças acumulando anormalidades cromossômicas e produzindo incrementos na proporção de plântulas anormais (Lin, 1988).

Os resultados da Figura 1D indicam que houve um aumento do valor de condutividade elétrica na temperatura de $35{ }^{\circ} \mathrm{C}$ sobretudo nos primeiros 3 meses de armazenamento porém após este período a variação foi menor devido principalmente à redução do teor de água dos grãos (Figura 1A) que, de início, era de $14,31 \%$ e reduziu para $7,79 \%$ ao final de 12 meses de armazenamento. A condutividade elétrica aumentou na temperatura de $25{ }^{\circ} \mathrm{C}$ permanecendo constante para os tratamentos de 5 e $15^{\circ} \mathrm{C}$ visto que temperaturas baixas reduzem as alterações nos grãos permitindo o armazenamento seguro por períodos mais longos.

Segundo Costa et al. (2010) e Faroni et al. (2005), a leitura da condutividade elétrica pode ser utilizada para avaliar o vigor pois está relacionada com a quantidade de íons lixiviados na solução e a integridade das membranas celulares sendo que membranas desestruturadas e danificadas, resultado do armazenamento incorreto, elevam o valor da condutividade elétrica e, em contrapartida, reduzem o vigor dos grãos e sementes. De acordo com Rigueira et al. (2009), o processo de resfriamento da massa de grãos, com redução da temperatura durante o período de armazenagem, é uma técnica eficaz e econômica para a manutenção da qualidade do produto pois diminui a atividade da água, reduz a taxa respiratória dos grãos, retarda o desenvolvimento dos insetos-praga e da microflora presente, independentemente das condições climáticas da região, observados esses observados nas temperaturas de 5 e $15{ }^{\circ} \mathrm{C}$ em que os parâmetros fisiológicos de germinação e condutividade elétrica não apresentaram diferença ao longo de doze meses de armazenamento.

Os resultados do teor de lipídios (Figura 1E) indicam que não foram observadas alterações ao longo de doze meses de armazenamento nas temperaturas de 5, 15, 25 e $35{ }^{\circ} \mathrm{C}$. Os resultados diferem de Gutkoski et al. (2009), que encontraram redução no teor de lipídios ao avaliar grãos de milho armazenados em silo aerado com ar natural durante 120 dias; entretanto, o autor atribui esta redução ao maior tempo necessário para a secagem dos grãos a níveis seguros de armazenamento, sobremaneira na camada superior do silos, quando o tempo de secagem é mais elevado. A diminuição do teor de lipídios, segundo Antunes et al. (2011), acarreta problemas para a fabricação de rações de vez que a gordura é um dos constituintes mensurados na elaboração da dieta voltada para o ganho de peso de animais de corte comercial 
e a redução desses valores pode comprometer o rendimento dos animais porém com teor de água de $14 \%$ na faixa de temperatura de 5 a $35^{\circ} \mathrm{C}$, não foram observadas diferenças.

Os resultados do perfil de ácidos graxos (Tabela 2) indicam que houve redução dos ácidos graxos insaturados aos doze meses para os grãos armazenados na temperatura de 35 ${ }^{\circ} \mathrm{C}$, resultado da redução dos teores de ácidos linoleico e linolênico, que possuem 2 e 3 insaturações, respectivamente. Os resultados estão de acordo com Lee \& Cho (2012) que, ao avaliar o armazenamento de grãos de soja durante 24 meses em temperatura ambiente, encontraram redução dos ácidos graxos poli-insaturados e aumento do teor de ácido oleico, um ácido graxo monoinsaturado.

Tabela 2. Perfil de ácidos graxos de grãos de milho armazenados ao final de doze meses nas temperaturas de $5,15,25$ e $35^{\circ} \mathrm{C}$

\begin{tabular}{lrrrrr}
\hline \multicolumn{1}{c}{$\begin{array}{c}\text { Ácidos } \\
\text { graxos }\end{array}$} & \multirow{2}{*}{ Inicial $^{2}$} & $\mathbf{5}$ & $\mathbf{1 5}$ & $\mathbf{2 5}$ & $\mathbf{3 5}$ \\
\cline { 3 - 6 } C 16 & $12,50 \mathrm{a}$ & $12,45 \mathrm{a}$ & $12,37 \mathrm{a}$ & $12,45 \mathrm{a}$ & $12,73 \mathrm{a}$ \\
$\mathrm{C} 18$ & $2,72 \mathrm{a}$ & $2,60 \mathrm{a}$ & $2,60 \mathrm{a}$ & $2,54 \mathrm{a}$ & $2,66 \mathrm{a}$ \\
$\mathrm{C} 18: 1$ & $33,94 \mathrm{a}$ & $33,66 \mathrm{a}$ & $33,57 \mathrm{a}$ & $33,56 \mathrm{a}$ & $33,69 \mathrm{a}$ \\
$\mathrm{C} 18: 2$ & $50,18 \mathrm{a}$ & $50,09 \mathrm{a}$ & $50,27 \mathrm{a}$ & $50,28 \mathrm{a}$ & $49,80 \mathrm{~b}$ \\
C 18:3 & $1,24 \mathrm{a}$ & $1,20 \mathrm{a}$ & $1,20 \mathrm{a}$ & $1,28 \mathrm{a}$ & $1,11 \mathrm{~b}$ \\
Saturados & $15,02 \mathrm{a}$ & $15,04 \mathrm{a}$ & $14,97 \mathrm{a}$ & $14,98 \mathrm{a}$ & $15,40 \mathrm{~b}$ \\
Insaturados & $84,98 \mathrm{a}$ & $84,96 \mathrm{a}$ & $85,03 \mathrm{a}$ & $85,02 \mathrm{a}$ & $84,60 \mathrm{~b}$ \\
\hline
\end{tabular}

${ }^{1}$ Resultados expressos em \%.; As cadeias carbônicas correspondem aos seguintes ácidos graxos: ácido palmítico (C16), ácido esteárico (C 18), ácido oleico (C 18:1), ácido linoleico (C 18:2) e ácido linolênico (C 18:3); ${ }^{2}$ Médias aritméticas simples de três repetições seguidas por letras minúsculas iguais na mesma linha não diferem entre si $(p>0,05)$

A presença de duplas ligações na cadeia dos ácidos graxos os torna mais instáveis e, de acordo com Zadernowski et al. (1999), o aumento e a degradação de ácidos graxos ocorrem através da ação de enzimas lipases, peroxidases e fosfolipases presentes no próprio grão ou produzidas pela microflora associada, principalmente fungos. Segundo Morelló et al. (2004), os ácidos poli-insaturados, linolênico e linoleico são degradados durante o armazenamento reduzindo a qualidade dos grãos pois o óleo de milho possui composição de grande importância na dieta humana principalmente na prevenção de doenças cardiovasculares e no combate ao colesterol, além de fornecer outros compostos, como tocoferois e carotenoides, com potencial antioxidante.

\section{Conclusões}

1. Os resultados indicam ser possível armazenar grãos de milho nas temperaturas de $5,15,25$ e $35^{\circ} \mathrm{C}$ com umidade de $14 \%$ durante 6 meses, sem alterar a tipificação final do produto porém após este período há redução da qualidade dos grãos alterando a tipificação em todas as temperaturas de armazenamento utilizadas ao final de 12 meses, exceto em grãos armazenados na temperatura de $15^{\circ} \mathrm{C}$.

2. A utilização de temperaturas mais elevadas de armazenamento (acima de $15{ }^{\circ} \mathrm{C}$ ) provoca aumentos dos processos metabólicos dos grãos reduzindo o percentual de germinação e aumentando a condutividade elétrica dos grãos em especial na temperatura de $35^{\circ} \mathrm{C}$, mesmo com reduções dos teores de água que provocaram redução do peso dos grãos.

3. O teor de lipídios não é alterado ao longo dos 12 meses de armazenamento porém há redução dos teores de ácidos graxos poli-insaturados na temperatura de $35^{\circ} \mathrm{C}$.

\section{Agradecimentos}

À CAPES (Coordenação de Aperfeiçoamento de Pessoal de Nível Superior), ao CNPq (Conselho Nacional de Desenvolvimento Científico e Tecnológico), à SCT-RS (Secretaria da Ciência, Inovação e Desenvolvimento Técnológico do Estado do Rio Grande do Sul) e ao Polo de Inovação Tecnológica em Alimentos da Região Sul.

\section{Literatura Citada}

AACC - American Association of Cereal Chemists. Aproved methods AACC, 9.ed. St. Paul: AACC, 1995.

Aguiar, R. W. S.; Brito, D. R.; Ootani, M. A.; Fidelis, R. R.; Peluzio, J. N. Efeito do dióxido do carbono, temperatura e armazenamento sobre sementes de soja e micoflora associada. Revista Ciência Agronômica, v.43, p.554-560, 2012. http://dx.doi.org/10.1590/ S1806-66902012000300019

Antonello, L. M.; Muniz, M. B.; Brand, S. C.; Vidal, M. D.; Garcia, D.; Ribeiro, L.; Santos, V. Qualidade de sementes de milho armazenadas em diferentes embalagens. Ciência Rural, v.39, p.2191-2194, 2009. http://dx.doi.org/10.1590/S010384782009005000157

Antunes, L. E.G.; Viebrantz, P. C.; Gottardi, R.; Dionello, R. G. Características físico-químicas de grãos de milho atacados por Sitophilus zeamais durante o armazenamento. Revista Brasileira de Engenharia Agrícola e Ambiental, v.15, p.615-620, 2011. http:// dx.doi.org/10.1590/S1415-43662011000600012

ASAE - American Society of Agricultural Engineers. Moisture measurement - Unground grain and seeds, St. Joseph: ASAE, 2000. 563p.

Brackmann, A.; Neuwald, D. A.; Ribeiro, N. D.; Freitas, S. T. Conservação de três genótipos de feijão (Phaseolus vulgaris L.) do grupo carioca em armazenamento refrigerado e em atmosfera controlada. Ciência Rural, v.32, p.911-915, 2002. http://dx.doi. org/10.1590/S0103-84782002000600001

Brasil. Ministério da Agricultura, Pecuária e Abastecimento. Regras para análise de sementes / Ministério da Agricultura, Pecuária e Abastecimento. Secretaria de Defesa Agropecuária. Brasília: MAPA/ACS, 2009, 399p.

Brasil. Mistério da Agricultura, Pecuária e Abastecimento. Instrução Normativa ${ }^{\circ} 60$, de 22 de dezembro de 2011. Regulamento Técnico do Milho. Diário Oficial da União. 23.12.2011, Brasília, DF.

Carneiro, L. M. T. A.; Biagi, J. D.; Freitas, J. G.; Carneiro, M. C.; Felício, J. C. Diferentes épocas de colheita, secagem e armazenamento na qualidade de grãos de trigo comum e duro. Bragantia, v.64, p.127137, 2005. http://dx.doi.org/10.1590/S0006-87052005000100014

CONAB - Companhia Nacional de Abastecimento . $12^{\circ}$ Levantamento Grãos Safra 2012/2013 - SET /13. <http://www.conab.gov.br/ OlalaCMS/uploads/arquivos/13_10_16_14_32_01_boletim_ portugues_-_setembro_2013.pdf>28 Out. 2013.

Costa, A. R.; Faroni, L. R. D.; Alencar, E. R.; Carvalho, M. C. S; Ferreira, L. G. Qualidade de grãos de milho armazenados em silos bolsa. Revista Ciência Agronômica, v.41, p.200-207, 2010. http:// dx.doi.org/10.1590/S1806-66902010000200005

Faroni, L. R. A.; Barbosa, G. N. O.; Sartori, M. A.; Cardoso, F. S.; Alencar, E. R. Avaliação qualitativa e quantitativa do milho em diferentes condições de armazenamento. Engenharia na Agricultura, v.13, p.193-201, 2005. 
Gutkoski, L. C; Eichelberger, L.; Santin, J. A.; Portella, J. A.; Spier, F.; Colussi, R. Avaliação da composição química de milho seco e armazenado em silo tipo alambrado com ar natural forçado. Ciência e Tecnologia de Alimentos, v.29, p.879-885, 2009. http:// dx.doi.org/10.1590/S0101-20612009000400028

Hartman, L.; Lago, B. C. A rapid preparation of fatty methyl esters from lipids. Laboratory Practice, v.22, p.475-477, 1973.

ISTA - International Seed Testing Association; Determination of other seeds by number. In: International rules for seed testing. Bassersdorf, 2008. Cap.4, p.4.1-4.3.

Lee, J. H.; Cho, K. M. Changes occurring in compositional components of black soybeans maintained at room temperature for different storage periods. Food Chemistry, v.131, p.161-169, 2012. http:// dx.doi.org/10.1016/j.foodchem.2011.08.052

Lin, S. S. Efeito do período de armazenamento na lixiviação eletrolítica dos solutos celulares e qualidade fisiológica da semente de milho (Zea mays L.) e feijão (Phaseolus vulgaris L.). Revista Brasileira de Sementes, v.10, p.59-67, 1988.

Morelló, J. R.; Motilva, M. J.; Tovar, M. J.; Romero, M. P. Changes in commercial virgin olive oil (cv Arbequina) during storage, with special emphasis on the phenolic fraction. Food Chemistry, v.85, p.357-364, 2004. http://dx.doi.org/10.1016/j. foodchem.2003.07.012

Oliveira, V. R. de; Ribeiro, N. D.; Maziero, S. M.; Cargnelutti Filho, A.; Jost, E. Qualidade para o cozimento e composição nutricional de genótipos de feijão com e sem armazenamento sob refrigeração. Ciência Rural, v.41, p.746-752, 2011. http://dx.doi.org/10.1590/ S0103-84782011005000050

Park, C. E.; Kim, Y. S.; Park, K. J.; Kim, B. K. Changes in physicochemical characteristics of rice during storage at different temperatures. Journal of Stored Products Research, v.48, p.25-29, 2012. http://dx.doi.org/10.1016/j.jspr.2011.08.005
Perez-Garcia, F.; Gonzalez-Benito, M. E. Seed germination of five Helianthemum species: Effect of temperature and presowing treatments. Journal of Arid Environments, v.65, p.688-693, 2006. http://dx.doi.org/10.1016/j.jaridenv.2005.10.008

Reed, C.; Doyungan, S.; Ioerger, B.; Getchell, A. Response of storage molds to different initial moisture contents of maize (corn) stored at $25^{\circ} \mathrm{C}$, and effect on respiration rate and nutrient composition. Journal of Stored Products Research, v.43, p.443-458, 2007. http:// dx.doi.org/10.1016/j.jspr.2006.12.006

Rehman, Z. U.; Habib, F.; Zafar, S. I. Nutritional changes in maize (Zea mays) during storage at three temperatures. Food Chemistry, v.77, p.197-201, 2002. http://dx.doi.org/10.1016/S0308-8146(01)00337-5

Rigueira, R. J. A.; Lacerda Filho, A. F.; Volk, M. B. S. Avaliação da qualidade do feijão armazenado em ambiente refrigerado. Alimentos e Nutrição, v.20, p.649-655, 2009.

Rios, A. O.; Abreu, C. M. P.; Corrêa, A. D. Efeito da estocagem e das condições de colheita sobre algumas propriedades físicas, químicas e nutricionais de três cultivares de feijão (Phaseolus vulgaris L.). Ciência e Tecnologia de Alimentos, v.23, p.39-45, 2003. http://dx.doi.org/10.1590/S0101-20612003000400008

Santos, C. M. R.; Menezes, N. L.; Villela, F. A. Alterações fisiológicas e bioquímicas em sementes de feijão envelhecidas artificialmente. Revista Brasileira de Sementes, v.26, p.110-119, 2004. http:// dx.doi.org/10.1590/S0101-31222004000100017

SAS Institute. SAS user's guide: statistics, Version 9.1. Cary: SAS Institute, 2002

Silva, J. S.; Afonso, A. D. L.; Lacerda Filho, A. F. Secagem e armazenagem de produtos agrícolas. In: Silva, J. S. Pré-processamento de produtos agrícolas. Juiz de Fora: Instituto Maria, 1995. p.395-462.

Zadernowski, R.; Polakowska, H. N.; Rashed, A. A. The influence of heat treatament on the activity of lipo and hidrophilic components of oat grain. Journal of Food Processing and Preservation, v.23, p.177191, 1999. http://dx.doi.org/10.1111/j.1745-4549.1999.tb00378.x 